\title{
Saberes migrantes
}

Oscar Vallejos

Hebe Vessuri en un texto que busca dar cuenta del proceso de institucionalización de la ciencia en los contextos periféricos llama la atención acerca de cómo la ciencia occidental organiza dos dispositivos sociales: uno para validar conocimiento y otro «para mover conocimientos de unos sitios a otros» (Vessuri, 1994: 201). El primer aspecto de la ciencia que suele reconocerse como su condición sustantiva, es el dispositivo de validación para el que se postulan diferentes nombres: contrastación, prueba, corroboración, ajuste, etcétera. El segundo empezó a visibilizarse a partir del interés por comprender los procesos de institucionalización de la ciencia en las regiones que no la habían producido y cuando se rompe lo que Marcos Cueto identifica como la superioridad cultural intrínseca de la ciencia. Sólo allí se pone en visibilidad tal condición.

Tematizar esta condición móvil del conocimiento y lo que se sigue de ello es el interés de esta nueva sección de El Hilo de la Fábula. La hemos llamado Saberes migrantes para recuperar una sensibilidad actual acerca del migrar que, si bien se presenta como un drama de esta cruda actualidad, no ha dejado de suceder a partir de la experiencia de la modernidad, la intensificación del capitalismo y la estructuración colonial.

La agenda de trabajo sobre los saberes migrantes que pasa a formar parte de los estudios comparados con derecho propio incita a pensar que los problemas epistemológicos - aquello que había sido considerada la condición sustantiva de la ciencia - deben sopesarse en contacto con las condiciones experienciales de quiénes y dónde producen saberes y cómo las zonas de realidad acerca de las que pretenden hablar no son necesariamente locales sino que parecen ingresar a una escena global. La perspectiva comparada nos incita a pensar que lo local no es ni un destino ni una zona dócil de lo real que se deja expresar; cuando se repone la dimensión migrante del saber se repone también la memoria del recorrido de unos sitios a otros, de unas lenguas a otras; de unas lenguas otras.

\section{Referencias}

Vessuri, Hebe (1994). «El proceso de institucionalización», en Salomon, Jean-Jacques y otros (Comp.). Una búsqueda incierta. Ciencia, tecnología y desarrollo. México: Editorial de la Universidad de las Naciones Unidas/FCE. 1996. [Traducción del texto en inglés de Susana Marín] 